\title{
Core/Combustor-Noise Baseline Measurements for the DGEN Aeropropulsion Research Turbofan
}

\author{
Devin K. Boyle ${ }^{\dagger}$ Brenda S. Henderson ${ }^{\ddagger}$ and Lennart S. Hultgren ${ }^{\ddagger}$ \\ National Aeronautics and Space Administration \\ John H. Glenn Research Center at Lewis Field \\ Cleveland, Ohio 44135, USA
}

\begin{abstract}
Contributions from the combustor to the overall propulsion noise of civilian transport aircraft are starting to become important due to turbofan design trends and advances in mitigation of other noise sources. Future propulsion systems for ultra-efficient commercial air vehicles are projected to be of increasingly higher bypass ratio from larger fans combined with much smaller cores, with ultra-clean burning fuel-flexible combustors. Unless effective noise-reduction strategies are developed, combustor noise is likely to become a prominent contributor to overall airport community noise in the future. The new NASA DGEN Aeropropulsion Research Turbofan (DART) is a cost-efficient testbed for the study of core-noise physics and mitigation. This paper describes the recently completed DART core/combustor-noise baseline test in the NASA GRC Aero-Acoustic Propulsion Laboratory (AAPL). Acoustic data were simultaneously acquired using the AAPL overhead microphone array in the engine aft quadrant farfield, a single midfield microphone, and two semi-infinite-tube unsteady pressure sensors at the core-nozzle exit. Combustor-noise components of measured total-noise signatures were educed using a two-signal source-separation method and are found to occur in the expected frequency range. The acoustic data compare well with results from a limited 2014 feasibility test and will serve as a high-quality baseline for future research using the DART. The research described herein is aligned with the NASA Ultra-Efficient Commercial Transport strategic thrust and is supported by the NASA Advanced Air Vehicle Program, Advanced Air Transport Technology Project, under the Aircraft Noise Reduction Subproject.
\end{abstract}

\section{Nomenclature}

\begin{tabular}{ll} 
AAPL & Aero-Acoustic Propulsion Laboratory \\
DART & DGEN Aero-Propulsion Research Turbofan \\
FADEC & full authority digital engine control [unit] \\
GRC & Glenn Research Center \\
ITP & infinite-tube-pressure [probe] \\
NATR & nozzle acoustic test rig \\
NI & National Instruments \\
$B P F_{\mathrm{F}}$ & fan blade-passing frequency \\
$B P F_{\mathrm{L}}$ & low-pressure-turbine blade-passing frequency \\
$N_{\mathrm{H}}$ & high-pressure-spool shaft speed, rpm \\
$N_{\mathrm{Lc}}$ & temperature-corrected low-pressure-spool shaft speed, rpm \\
$N_{\mathrm{L}}$ & low-pressure-spool shaft speed, rpm \\
$S P F_{\mathrm{H}}$ & high-pressure-spool shaft-passing frequency \\
$S P F_{\mathrm{L}}$ & low-pressure-spool shaft-passing frequency \\
$S P F_{\mathrm{F}}$ & fan shaft-passing frequency \\
$S P L$ & sound pressure level, dB re $20 \mu \mathrm{Pa}$ \\
$N P L$ & noise pressure level, dB \\
$O P R$ & overall pressure ratio \\
\hline$\dagger$ & $\begin{array}{l}\dagger \\
\ddagger\end{array}$ Associate Fellow AIAA
\end{tabular}




\section{Introduction}

Modern turbofan design trends promise overall quieter future propulsion systems for subsonic-transport aircraft. Notable emerging turbofan features include higher bypass ratios, wide-chord low-pressure-ratio fans, core turbomachinery with lower blade counts, lean combustors, and smaller cores with higher overall pressure ratios $(O P R)$. Several of these anticipated future engine characteristics are expected to either directly or indirectly increase combustor noise generation and propagation to external observers. In addition, other propulsion-noise sources are projected ${ }^{1}$ to be reduced by these engine design trends, as well as by expected advances in fan-noise mitigation. It is eviden ${ }^{11}$ that combustor noise will become an increasingly important component of the total propulsion noise signature at all engine power settings in the future. Consequently, combustor noise needs to be addressed in order to meet far-term noise goals guided by expected domestic and international regulatory airport-community-noise metrics.

Core noise conventionally includes contributions from the compressor, combustor and turbine. Generally, compressor noise, originating from rotor-stator and inter-stage interactions, propagates in the forward direction where it is masked by fan noise. Turbine rotor-stator interaction tones propagate mainly in the aft direction and occur at frequencies on the order of several $\mathrm{kHz}$. Turbine noise could become more important in the future ${ }^{2}$ due to the design trends of higher turbine-rotor blade loading and (the accompanying) lessening of turbine-stage solidity. However, it is believed here that acoustic treatment and the current cut-off/modal design techniques can be applied to control these effects. Combustor noise manifests as incoherent broadband noise in the less than $1.5 \mathrm{kHz}$ frequency range—on an $1 / 3$-octave basis, it is generally observed to peak around $300-500 \mathrm{~Hz}$. For current-generation turbofan engines, combustor noise can become prominent in the farfield during low power settings typical of commercial aircraft approach conditions, but it is typically overwhelmed by fan and jet noise at high engine-power settings during takeoff. However, combustor noise will likely be a crucial issue in meeting future regulatory noise metrics. In fact, the dominating noise sources for far-term concept aircraft are expected to originate, in alphabetical order, from the airframe, combustor, and fan, with the airframe noise being an issue mainly at approach.

In order to study propulsion noise production, propagation, diagnostics and, particularly, mitigation in a relevant environment, NASA has recently acquired a Price Induction DGEN 380 turbofan engine. The DGEN 380 is a two-spool $500 \mathrm{lbf}(2.2 \mathrm{kN})$ thrust-class geared turbofan engine with a bypass ratio of approximately 7.6 , a 3.32 fan gear ratio, a single centrifugal compressor on the high pressure spool, a reverse flow annular combustor, and single stage uncooled axial high-pressure and low-pressure turbines. Its modular design will allow the replacement of major components with parts modified for invasive instrumentation with comparative ease, thus promising to be a cost-effective research platform. This NASA resource has been designated as the DGEN Aero-Propulsion Research Turbofan (DART).

A baseline core/combustor-noise test using the DART in the Aero-Acoustic Propulsion Laboratory (AAPL) at NASA Glenn Research Center (GRC) was completed during late summer of 2017. The results and findings from this test are the subject of this paper. The test purpose was three-fold: (1) to establish a baseline dataset for future core/combustor-noise measurements, (2) to compare with results obtained during a 2014 feasibility test using a different DGEN 380 turbofan,, 3 and (3) to further the local hands-on experience in using state-of-the-art infinite-tubepressure (ITP) transducers for (remote) measurement of unsteady pressures in extreme environments.

From a core noise perspective, one of the goals of the earlier 2014 test was to evaluate the feasibility of the (then) DART concept as a combustor-noise research platform, ${ }^{3]}$ particularly with regard to how well the DGEN 380 's core/combustor-noise characteristics relate to those of current-generation combustors used in turbofan engines larger than the comparatively small DGEN 380. Hultgrer ${ }^{3}$ used a well-established two-signal source separation technique (Ref. 4. Ch. 4) to educe the low-frequency broadband combustor-noise component of the total aft-radiated noise. A core-exhaust-mounted ITP was used in conjunction with a midfield microphone located $12 \mathrm{ft}$ from the engine axis at engine centerline height and a $130^{\circ}$ polar angle. Combustor noise was detected in the expected frequency range of approximately $100-500 \mathrm{~Hz}$ with a spectral shape typical of turbofan combustor noise. The DART concept was deemed to be a relevant and valuable asset for studying core-noise physics and evaluating novel measurement techniques. The recent 2017 test, in a sense, is a more extensive repeat of the limited 2014 one, with improved instrumentation and simultaneous acoustic data also acquired in the farfield.

\section{Experimental Setup}

The DART core/combustor-noise baseline test was performed in the AAPL at NASA GRC in August 2017. The coordinate system used to describe measurement locations herein is a spherical one with its origin located on the the engine centerline at the core-nozzle exit plane. The polar angle is zero in the inlet direction and the azimuthal angle is 
zero in the engine port-side horizontal plane.

The turbofan engine was located near the center of the AAPL dome allowing use of the fixed overhead microphone array. In the past, this array has been used extensively in connection with the Nozzle Acoustic Test Rig (NATR). Only a subset of the 24 microphone locations was utilized in this test. Seven G.R.A.S. (type 46BE) 1/4-inch prepolarized condenser-type microphones were mounted in the aft portion of the overhead array and oriented such that their faces pointed at the center of the core-exhaust plane. Polar angles ranged from approximately $108^{\circ}$ to $143^{\circ}$ at radial distances from the engine core exit of 36-39 ft (11-12 m). The azimuthal angles of the overhead-array microphones were nearly constant at $83^{\circ}$ with a slight variation due to the out-of-azimuthal-plane rotation of the array. The mean distance between the overhead-array measurement locations and the core-nozzle exit is approximately 51 nozzle diameters. The overhead microphones can thus be considered to be in the farfield, according to the criteria given by Ahuja ${ }^{5} \mathrm{~A}$ view of the AAPL overhead array from floor-level near the location of the engine is seen in Fig. 1 The aft-most microphone locations, except for the last one seen at the bottom of the image, were used in this test. The microphones will be referred to here as sensors FF017 through FF023, with the 'FF' indicating farfield and the numerical part being consistent with the AAPL overhead-array microphone-numbering convention and increasing with aft position.

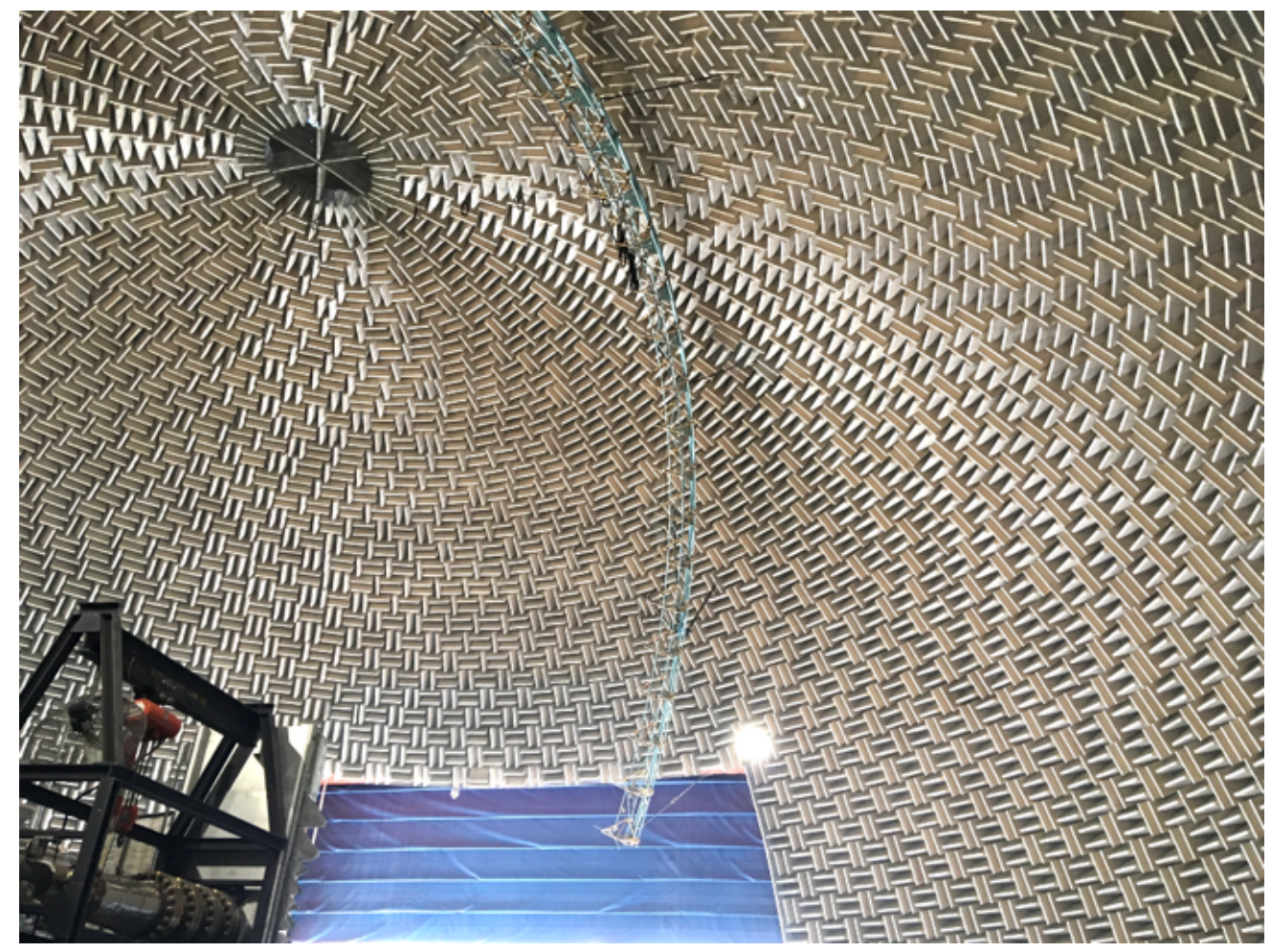

Figure 1. AAPL overhead microphone array (aqua arc)

Table 1. Microphone locations in spherical coordinates

\begin{tabular}{|c|c|c|c|c|c|c|c|c|}
\hline & FF017 & FF018 & FF019 & FF020 & FF021 & FF022 & FF023 & MF101 \\
\hline $\begin{array}{c}\text { radius, ft } \\
(\mathrm{m})\end{array}$ & $\begin{array}{c}39.56 \\
(12.06)\end{array}$ & $\begin{array}{c}38.81 \\
(11.83)\end{array}$ & $\begin{array}{c}38.25 \\
(11.66)\end{array}$ & $\begin{array}{c}37.55 \\
(11.44)\end{array}$ & $\begin{array}{c}37.05 \\
(11.29)\end{array}$ & $\begin{array}{c}36.63 \\
(11.16)\end{array}$ & $\begin{array}{c}36.57 \\
(11.15)\end{array}$ & $\begin{array}{c}10.0 \\
(3.05)\end{array}$ \\
\hline polar, $^{\circ}$ & 108.0 & 113.5 & 119.2 & 125.2 & 131.2 & 137.2 & 143.4 & 130.0 \\
\hline azimuth, $^{\circ}$ & 83.0 & 83.0 & 83.0 & 83.0 & 83.9 & 84.7 & 87.2 & 0 \\
\hline
\end{tabular}

In addition to microphones mounted in the aft portion of the overhead array, a single midfield microphone (identical to the overhead ones) was placed at a radial distance of $10 \mathrm{ft}(3.05 \mathrm{~m})$, at the engine centerline height, and at a polar angle of $130^{\circ}$. It will be referred to herein as sensor MF101, with the 'MF' indicating midfield. This microphone served dual purposes: first, allowing a simple comparison between the data acquired in 2014, wherein a circumferential array of midfield microphones was trained on the engine at a radius of $12 \mathrm{ft}(3.66 \mathrm{~m})$; and second, the midfield microphone in conjunction with an overhead-array microphone, in essentially the same polar direction, can provide some indication about how well the overhead measurement locations represent the true acoustic farfield. The 
microphone layout is described in Table 1

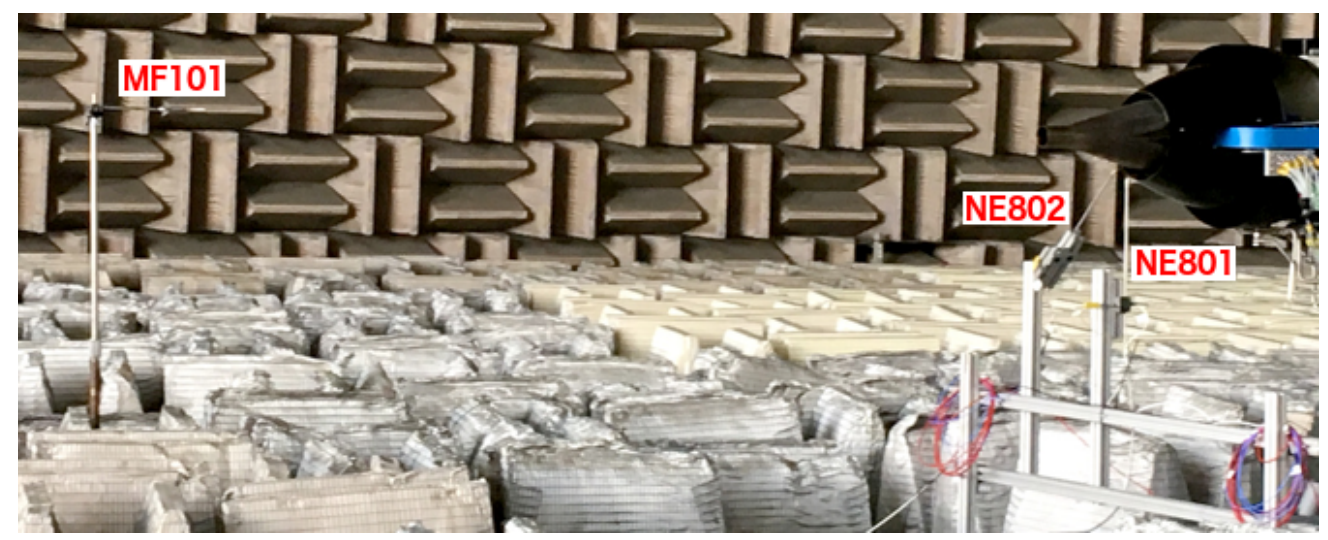

Figure 2. MF101 midfield microphone; NE801 and NE802 ITPs at DART core exit

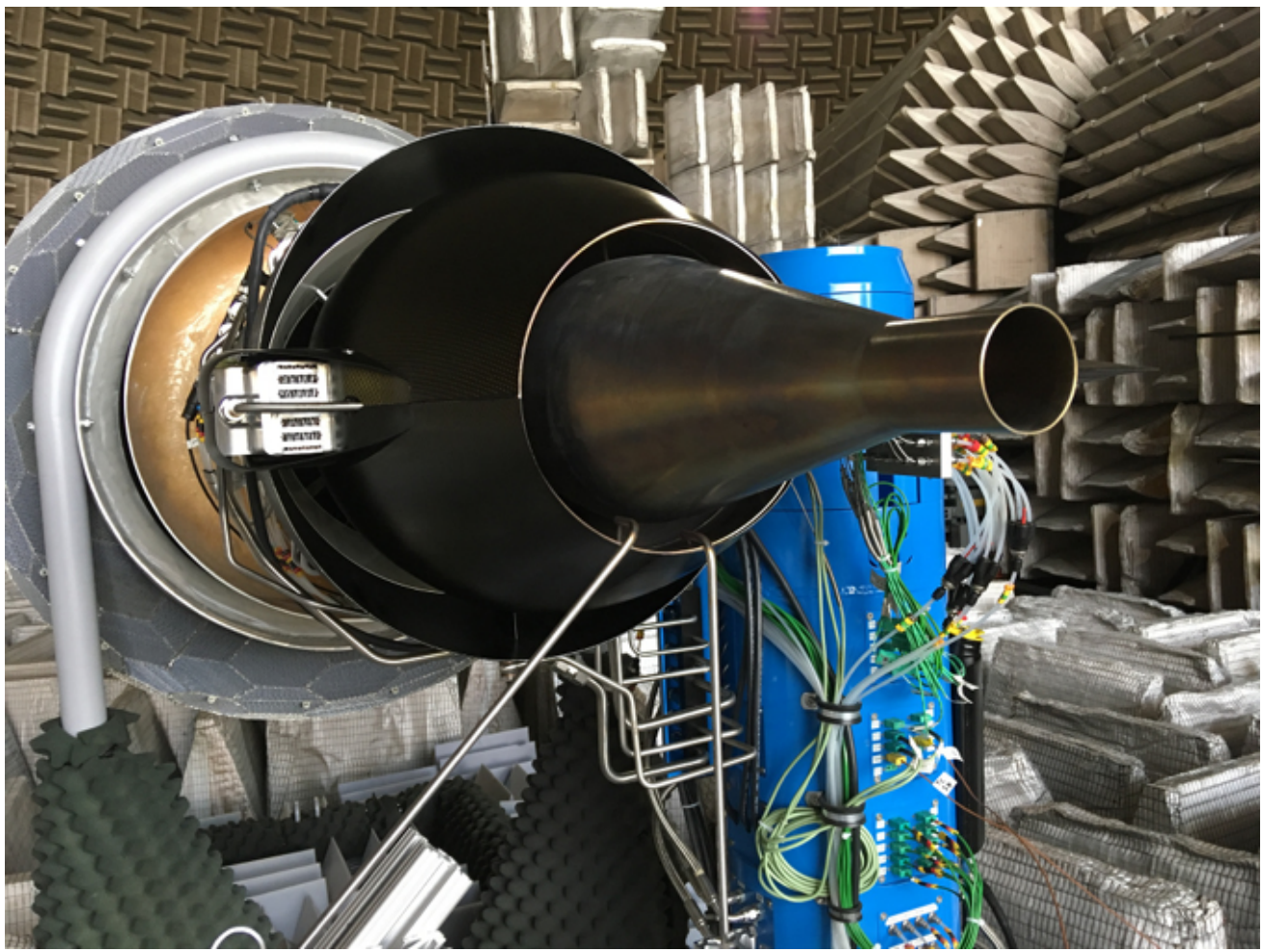

Figure 3. 6 o'clock (NE801) and 7 o'clock (NE802) ITPs at DART core-nozzle exit

Two Kulite ${ }^{\circledR}$ XCS-190-10D 10 psi $(68.95 \mathrm{kPa})$ differential unsteady pressure transducers were also installed, in an ITP configuration, at the core-nozzle exit providing engine-internal measurements. The stand-mounted midfield microphone and core-nozzle-exit ITPs are shown in Fig. 2 Figure 3 shows the location of the ITPs in more detail. In what follows, the 6 o'clock and 7 o'clock ITPs will be referred to as sensors NE801 and NE802, respectively, with the 'NE' indicating (core) nozzle exit. There is an approximately $1 \mathrm{ft}(0.305 \mathrm{~m})$ sense line beginning at the plane of the core-nozzle exit (actually just inside the core nozzle), leading to a steel block where the pressure transducer and a thermocouple are flush-mounted to the inner wall of the sense line. The flush mounting minimizes cavity noise, as well as resonances, associated with any volume between the transducer face and the tube inner diameter. The thermocouple is also flush mounted to avoid misleading pressure wave reflections or distortions. On the other side of the block, the infinite line is $50 \mathrm{ft}(15.24 \mathrm{~m})$ long, terminating at a tee connecting to the other ITP plumbing and a $\mathrm{N}_{2}$ gaseous nitrogen purge-flow supply line. The inner diameter of 0.194 in $(4.93 \mathrm{~mm})$ is maintained throughout to avoid 
any diameter discontinuities, which also would lead to pressure reflections/distortions. The nitrogen valve remained closed for the duration of the testing, since purge-flow cooling was found to be unnecessary for measurements at the core-exit location. Consequently, the main heat-transfer mechanism to the transducers was conduction since they are placed well outside of the core and fan streams. The transducers' 10 psi differential pressure range made it acceptable to vent each transducer's reference-pressure side to atmospheric conditions. The ITP design is pictured in Fig. 4

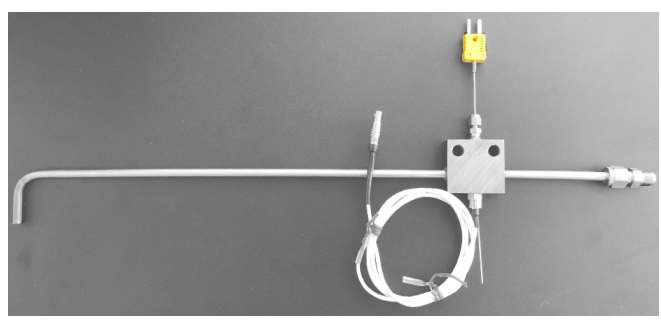

Figure 4. Infinite-Tube-Probe (ITP) design; sense line (left), connector to infinite line (right), thermocouple (top), and differential pressure transducer (bottom)

\section{Data Acquisition and Processing}

Data acquisition was achieved via a National Instruments ${ }^{\mathrm{TM}}$ (NI) PXIe-1082 chassis, utilizing two NI 4499 analogto-digital converter cards, simultaneously recording eight microphone channels and two ITP channels. The Kulite ${ }^{\circledR}$ pressure transducer signals were routed through a two-channel Kulite ${ }^{\circledR}$ KSC-2 signal conditioner that performed analog gain prior to the signals entering the NI data-acquisition chassis. The signals were digitized at 100,000 samples per second for a total observation time of 60 seconds at each experimental test point. The resulting time series for each channel and observation contains 6 million data points. Each time series was analyzed using an FFT length of 16,384 points (corresponding approximately to a $6.1 \mathrm{~Hz}$ frequency resolution or binwidth), Hamming windowing, and a 50 percent data-segment overlap. The resulting narrowband spectra are then the average of a large number of realizations (over 700 instantaneous spectra). Auto-spectra were computed using both the built-in capabilities of NI LabVIEW software that was used to control the data acquisition and post-test using MATLAB scripts and routines. Cross-spectra were computed using MATLAB with time-of-flight corrections applied to the microphone signals when appropriate.

\section{Results}

\section{A. Test Matrix}

DART's full authority digital engine control (FADEC) unit has an executable program that runs through a sequence of predefined engine power settings, with each setting here set to be held for 120 seconds. During normal engine operation, the temperature-corrected low-pressure-shaft speed $\left(N_{\mathrm{Lc}}\right)$ is used as the output value controlled by the FADEC. This corrected shaft speed is given by

$$
N_{\mathrm{Lc}}=N_{\mathrm{L}} \sqrt{T_{\mathrm{SLS}} / T_{\mathrm{amb}}}
$$

where $N_{\mathrm{L}}$ is the actual shaft speed, $T_{\mathrm{SLS}}=288.15 \mathrm{~K}$ is the sea-level standard temperature, and $T_{\mathrm{amb}}$ is the ambient temperature (also in $\mathrm{K}$ ).

The campaign consisted of the test points shown in Table 2, where the power setting represents the ratio of $N_{\mathrm{Lc}}$ to the maximum allowable $N_{\mathrm{L}}$ at standard sea-level conditions. The control program starts at idle (33\%) and dwells at each of the power settings shown in Table 2. After having reached the maximum available power setting (limited by the ambient temperature), it then returns to idle, and the sequence is then repeated once. Consequently, data were collected four times at the idle set point and twice at each of the other engine-power set points. Note that the maximum-power set point depends on the ambient temperature and this is why the engine

Table 2. DART core/combustor-noise baseline test matrix

\begin{tabular}{|c|c|c|c|}
\hline Point \# & Power, \% & Point \# & Power, \% \\
\hline 1 & 33 & 9 & 33 \\
\hline 2 & 33 & 10 & 33 \\
\hline 3 & 50 & 11 & 50 \\
\hline 4 & 60 & 12 & 60 \\
\hline 5 & 70 & 13 & 70 \\
\hline 6 & 80 & 14 & 80 \\
\hline 7 & 90 & 15 & 90 \\
\hline 8 & 92.5 & 16 & 92.3 \\
\hline & & 17 & 0 \\
\hline
\end{tabular}


power differs slightly between test point 8 and 16. Test point 17 was taken with the engine off, but with support systems (such as the oil pump, etc.) running, for a background-noise assessment.

Under FADEC command, the engine performed quite repeatably in maintaining shaft speed for a given set point. Figure 5 demonstrates the stability with which DART's actual $N_{\mathrm{L}}$ followed the commanded set point. Note that during the starting process, DART is controlled by the high-pressure-shaft speed, $N_{\mathrm{H}}$. Once the engine thermally stabilizes at idle power and the program is executed, it becomes controlled through $N_{\mathrm{Lc}}$. During the test, the actual low-speed-shaft rotation rate, $N_{\mathrm{L}}$, had an $\mathrm{rms}$ deviation of less than $0.04 \%$ and its maximum observed deviation was less than $0.1 \%$.

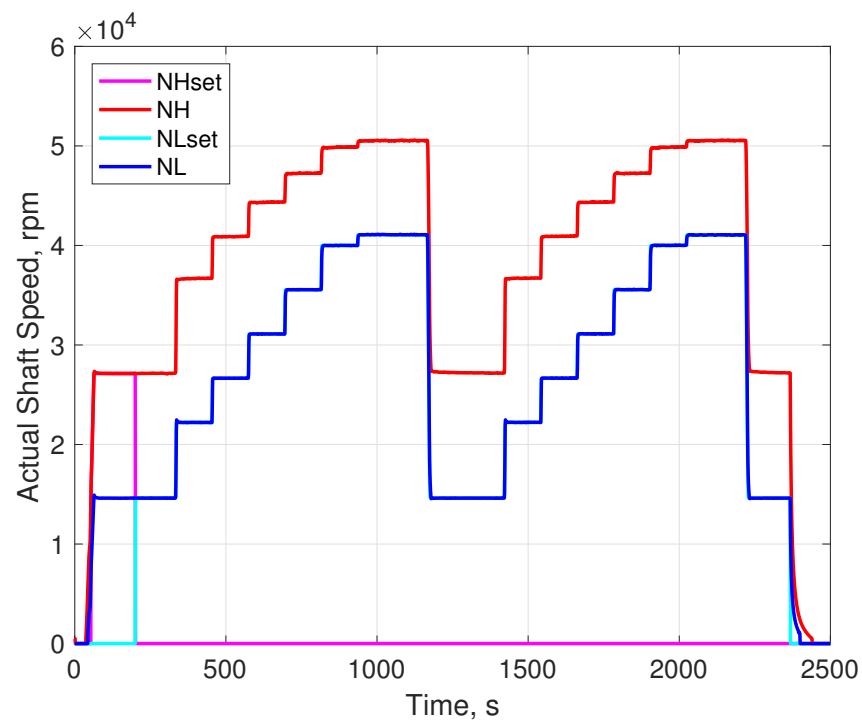

Figure 5. $N_{\mathrm{L}}$ and $N_{\mathrm{H}}$ set points and corresponding actual shaft speeds

Some frequencies of interest are listed in Table 3 , including shaft-passing frequencies for the high-pressure spool, $S P F_{\mathrm{H}}$, low-pressure spool, $S P F_{\mathrm{L}}$, and the fan shaft, $S P F_{\mathrm{F}}$. Fan and low-pressure-turbine blade passing frequencies, $B P F_{\mathrm{F}}$ and $B P F_{\mathrm{L}}$, respectively, round off the remainder of the columns in Table 3 As will be seen below, many of these tones are apparent either in the sound-pressure-level (SPL) spectra or in the 2-signal coherence spectra. However, the $B P F_{\mathrm{L}}$ tone only falls within the $10 \mathrm{kHz}$ limit of the spectra presented here for the idle power settings.

Table 3. Low/high-pressure-spool and fan shaft frequencies and fan/low-pressure-turbine blade-passing frequencies

\begin{tabular}{|c|c|c|c|c|c|c|}
\hline Point \# & Power, $\%$ & $S P F_{\mathrm{H}}, \mathrm{Hz}$ & $S P F_{\mathrm{L}}, \mathrm{Hz}$ & $S P F_{\mathrm{F}}, \mathrm{Hz}$ & $B P F_{\mathrm{L}}, \mathrm{Hz}$ & $B P F_{\mathrm{F}}, \mathrm{Hz}$ \\
\hline 1 & 33 & 452 & 244 & 73 & 9253 & 1027 \\
\hline 2 & 33 & 453 & 244 & 73 & 9256 & 1027 \\
\hline 3 & 50 & 611 & 370 & 112 & 14069 & 1561 \\
\hline 4 & 60 & 681 & 444 & 134 & 16884 & 1874 \\
\hline 5 & 70 & 739 & 518 & 156 & 19701 & 2186 \\
\hline 6 & 80 & 787 & 593 & 179 & 22518 & 2499 \\
\hline 7 & 90 & 831 & 667 & 201 & 25332 & 2811 \\
\hline 8 & 92.5 & 842 & 685 & 206 & 26022 & 2888 \\
\hline 9 & 33 & 454 & 244 & 73 & 9255 & 1027 \\
\hline 10 & 33 & 453 & 244 & 73 & 9256 & 1027 \\
\hline 11 & 50 & 612 & 370 & 112 & 14074 & 1562 \\
\hline 12 & 60 & 682 & 445 & 134 & 16890 & 1874 \\
\hline 13 & 70 & 739 & 519 & 156 & 19707 & 2187 \\
\hline 14 & 80 & 787 & 593 & 179 & 22521 & 2499 \\
\hline 15 & 90 & 831 & 667 & 201 & 25337 & 2812 \\
\hline 16 & 92.3 & 842 & 684 & 206 & 26002 & 2885 \\
\hline
\end{tabular}




\section{B. Repeatability and Signal-to-Noise Ratio}

Excellent measurement repeatability and signal-to-noise ratio were demonstrated in this test, as indicated by Fig. 6 Narrowband $(6.1 \mathrm{~Hz}$ binwidth) SPL for both ITPs, the midfield microphone and the farfield microphone oriented approximately at a $130^{\circ}$ polar angle are shown in the different panels of this figure. All plots are displaying data taken during the four test points at the $33 \%$ power setting as well as the background-noise measurement test point. The black curve in each plot is the spectrum for the sensor during the background noise condition with the engine not running. It should be noted that while the engine was not operating during this test point, other ancillary equipment like the fuel pump was running. Nevertheless, the signal-to-noise ratio is greater than $10 \mathrm{~dB}$ all the way down to below $100 \mathrm{~Hz}$ for all sensor locations; this is important because combustion broadband noise occurs primarily between about $100 \mathrm{~Hz}$ and $1 \mathrm{kHz}$.

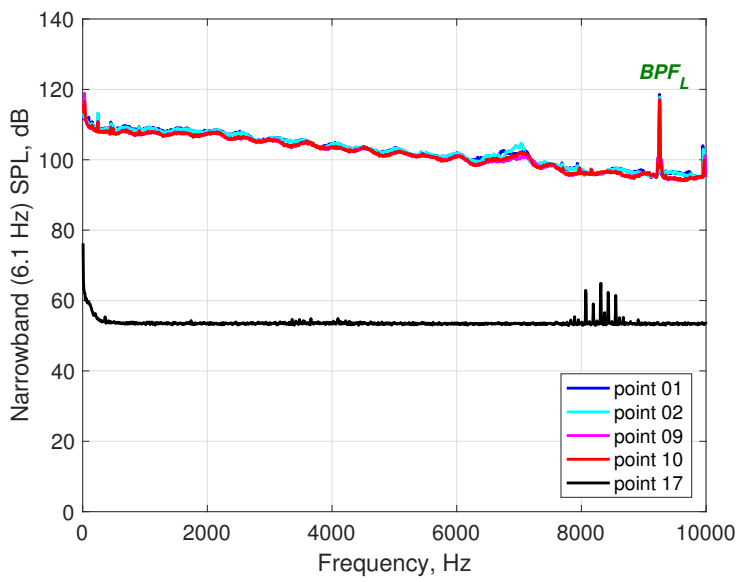

(a)

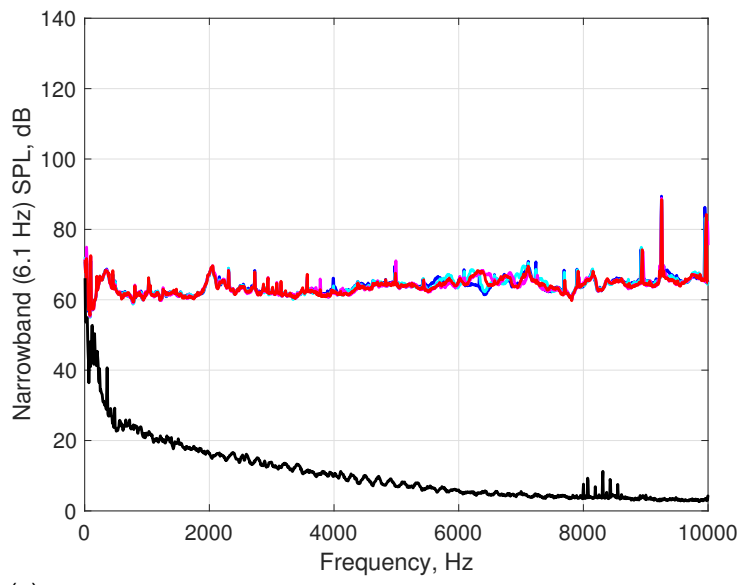

(c)

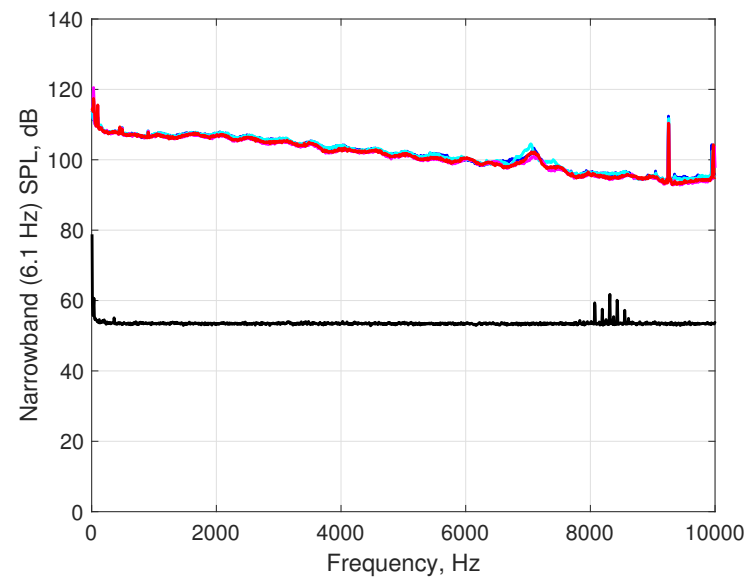

(b)

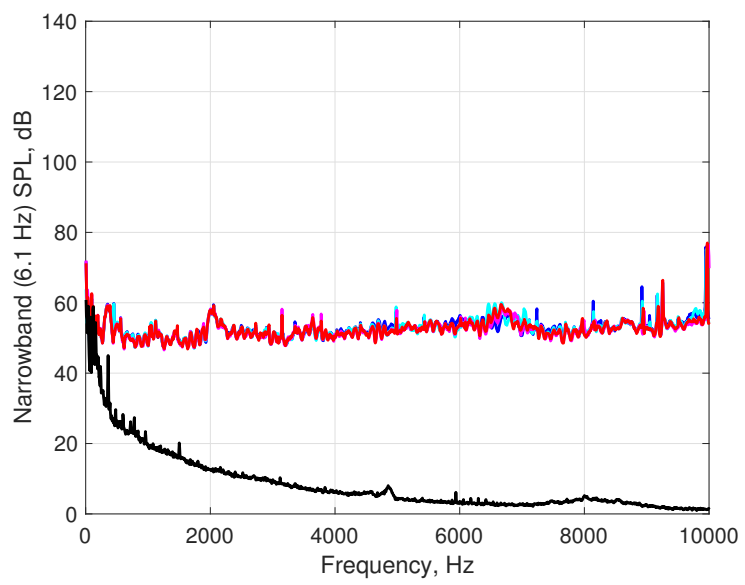

(d)

Figure 6. Narrowband (6.1 Hz binwidth) SPL spectra for both ITPs, the midfield microphone and the farfield microphone at approximately $130^{\circ}$ polar angle at engine-idle and background-noise (black curves) conditions: (a) 6 o'clock ITP, NE801; (b) 7 o'clock ITP, NE802; (c) midfield microphone, MF101; (d) farfield microphone, FF021

\section{Comparison with the 2014 Test}

Select data from the 2014 DGEN 380 test were then compared to the current data set. For the 2014 test, a single absolute pressure transducer was mounted in the bottom dead center ( 6 o'clock) position of the core exhaust. The lead time to get ready for the 2014 test was very short and, unfortunately, an absolute pressure transducer had to be used due to the long ordering/delivery times for suitable differential transducers. Hultgren ${ }^{3}$ defined a noise pressure level (NPL) which is the noise floor of the absolute transducer, accounting for the effects of nonlinearity, repeatability and hysteresis on output accuracy, which also defines a lower amplitude limit for unsteady pressure measurements 
using the absolute transducer. Hultgren ${ }^{3}$ deemed that signal-to-noise ratio was acceptable (greater than $10 \mathrm{~dB}$ ) for the frequency range of interest, i.e. below about $1 \mathrm{kHz}$.

Simultaneous data from this ITP and an aft-quadrant stand-mounted midfield microphone array, $12 \mathrm{ft}$ from the engine core exit and engine centerline height, were acquired during the 2014 test. Farfield overhead microphone-array data were also acquired, but not simultaneously with the ITP and the midfield array, during that test. The relevant 2014 data, discussed by Hultgren, $\frac{3}{3}$ were rescaled from a binwidth of $12.2 \mathrm{~Hz}$ to $6.1 \mathrm{~Hz}$ and the $130^{\circ}$ midfield microphone data were also adjusted from $12 \mathrm{ft}$ to the current $10 \mathrm{ft}$ distance assuming spherical spreading (no attenuation effects were applied). Figure 7 shows comparisons at comparable measurement locations. Once corrected to the same distance, both midfield microphone measurements agree well; the slight frequency difference between tones is a consequence of the $N_{\mathrm{Lc}}$-control of the engine set point, resulting in different actual shaft speeds due to differing ambient temperatures. The engine-mounted pressure-transducer results agree reasonably well up to about $1 \mathrm{kHz}$, but the absolute-transducer curve quickly deviates from the differential-transducer curves beyond $1 \mathrm{kHz}$. As expected, levels increase with engine power.

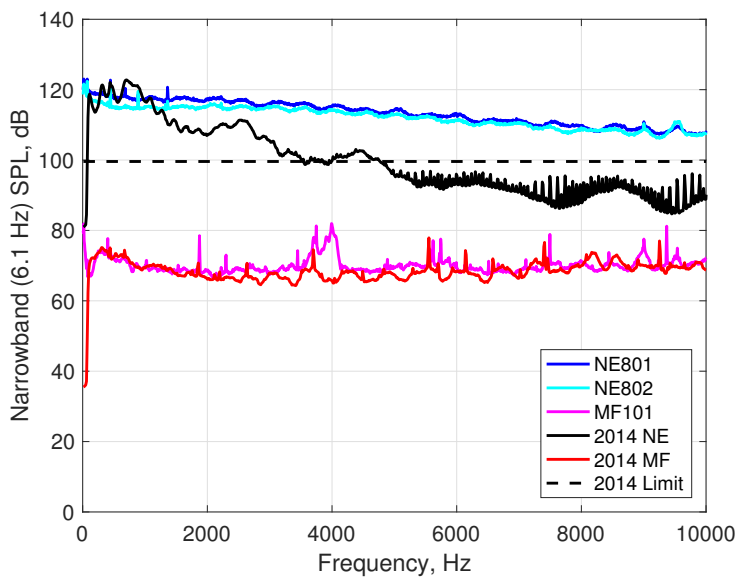

(a)

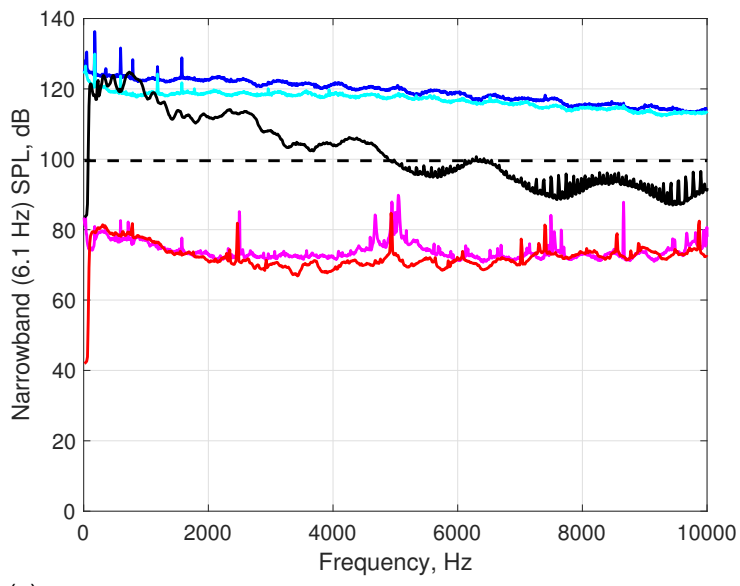

(c)

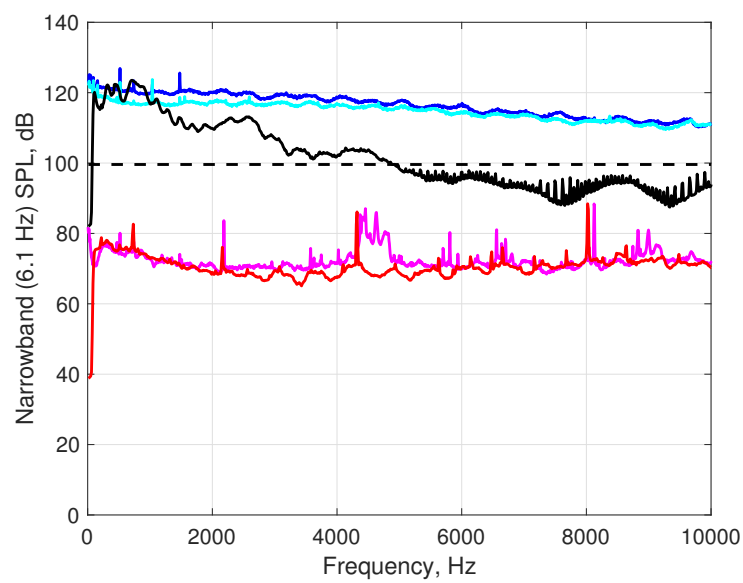

(b)

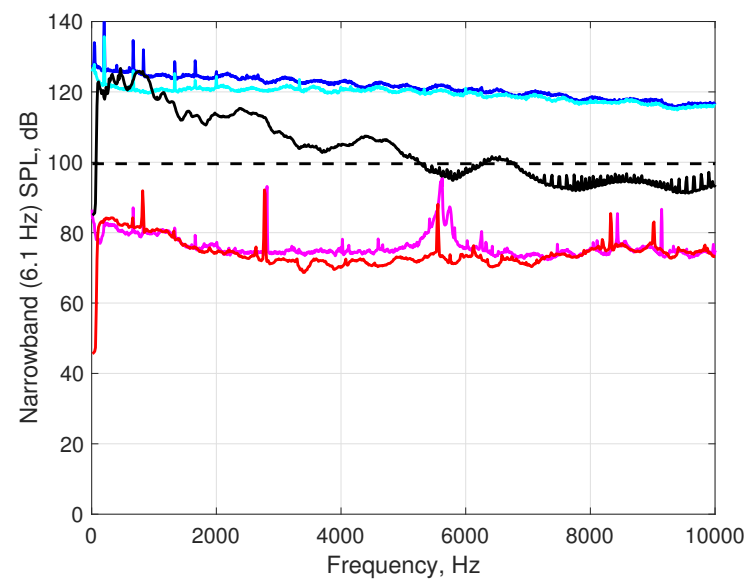

(d)

Figure 7. Narrowband (6.1 Hz binwidth) SPL spectra comparing ITP and midfield microphone results between 2014 and current test campaign (test points 4-7): a) $60 \%$, b) $70 \%$, c) $80 \%$, and d) $90 \%$ power settings

\section{Narrowband Sound-Pressure-Level Spectra}

Narrowband SPL spectra for both ITPs, the midfield microphone and the farfield microphone located at approximately $130^{\circ}$ polar angle are presented in Fig. 8 at four different power settings: $60 \%, 70 \%, 80 \%$, and $90 \%$. The fan bladepassing tone, $B P F_{\mathrm{F}}$, and several of its harmonics are present in the midfield and farfield microphone spectra. Some haystacking is observed around the second harmonic of the $B P F_{F}$. Since the ITP design included cylindrical tubes spanning the fan and core exit streams, it was necessary to determine whether some observed tones, or broader spec- 


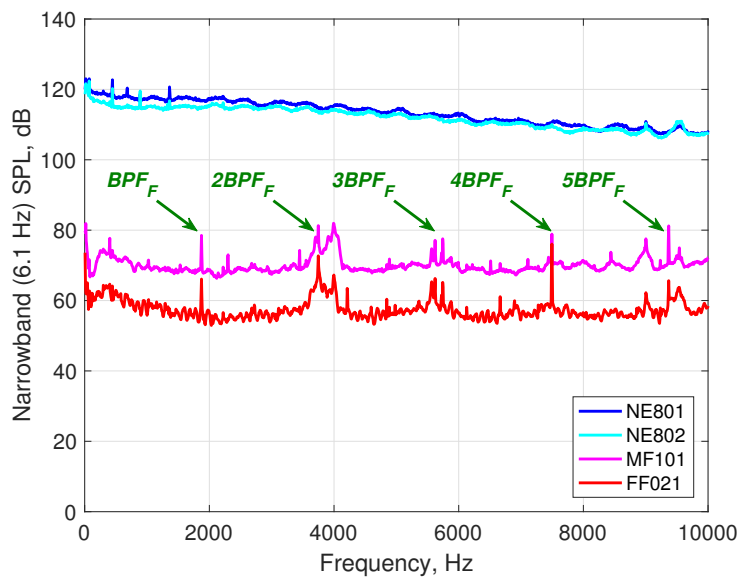

(a)

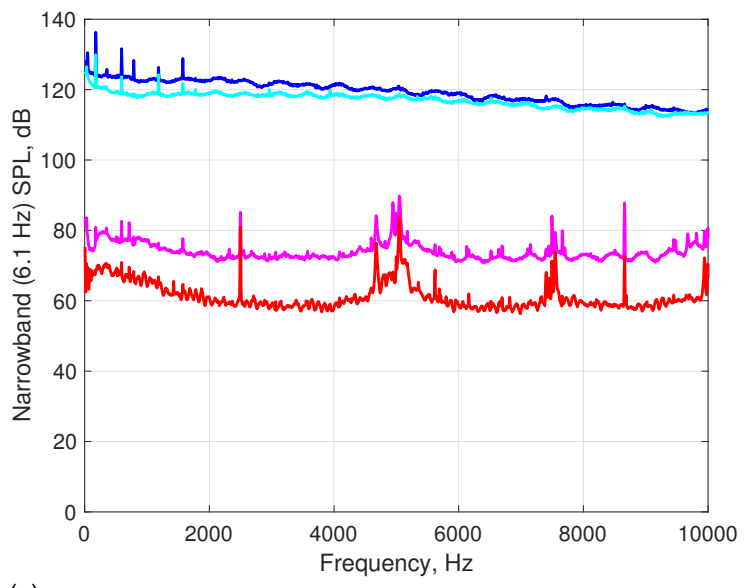

(c)

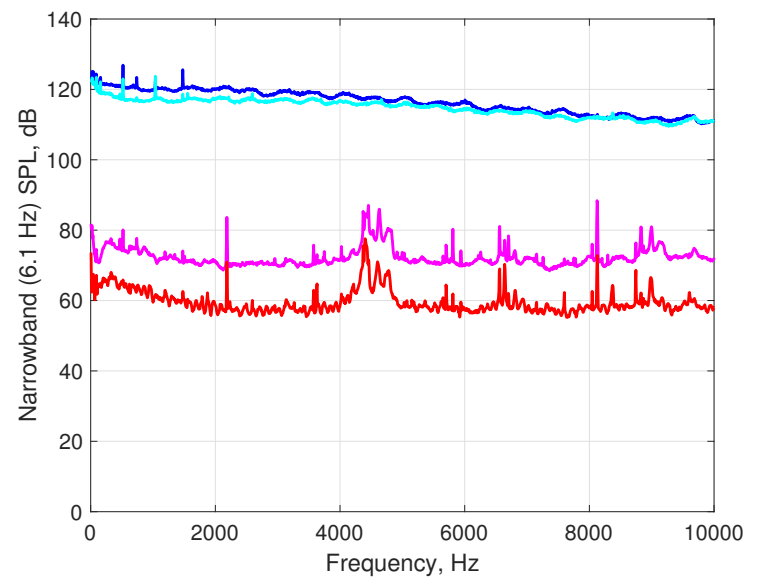

(b)

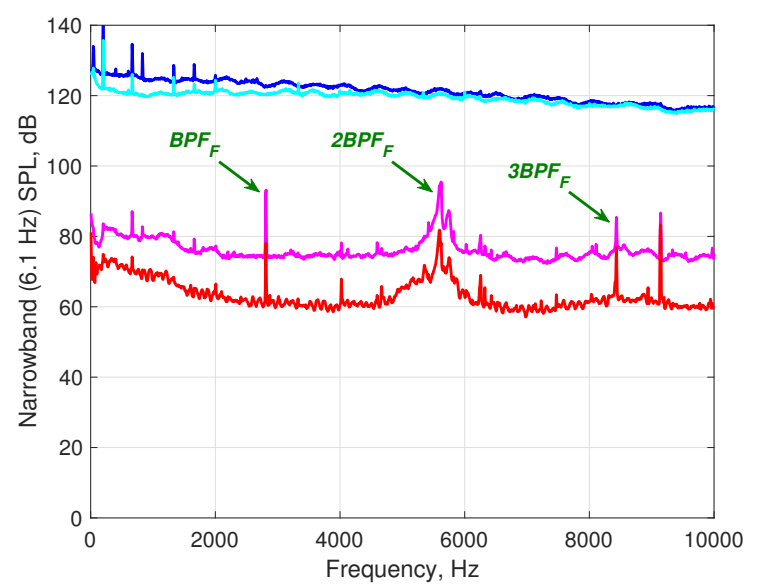

(d)

Figure 8. Narrowband (6.1 Hz binwidth) SPL spectra for both ITPs, mid- and far-field microphones at a) $60 \%$, b) $70 \%$, c) $80 \%$, and d) $90 \%$ power settings (test points 4-7)

tral peaks, could be attributed to vortex shedding from the cylinders. Based on the estimated shedding frequencies produced by the fan and core exhaust velocities and inspection of the SPL spectra, no clear evidence of ITP-tube vortex shedding could be identified. One anomaly (most pronounced for frequencies below about $4 \mathrm{kHz}$ ) is the divergence between the differential ITPs, NE801 (6 o'clock) and NE802 (7 o'clock), with increasing engine power setting. As of yet, the cause for this remains unclear.

\section{E. Core/Combustor-Noise Component}

Identification of core-noise components of the total noise signature was achieved through the two-signal coherence method (Ref. 4, Ch. 4), also known as the coherent output method. The use of this method involves the one-sided cross power spectrum, $G_{x y}$, between two signals measured at different locations, x and y, and the one-sided auto spectrum of each signal, $G_{x x}$ and $G_{y y}$. The magnitude-squared coherence is given by

$$
\gamma_{x y}^{2}=\frac{\left|G_{x y}\right|^{2}}{G_{x x} G_{y y}},
$$

where all of the quantities involved can be calculated from the recorded total noise signature data at the given locations.

The coherent output method then provides the estimate

$$
G_{v v}=\gamma_{x y}^{2} G_{y y}
$$

for the component $G_{v v}$ of the total measured spectra, $G_{y y}$, at a location of interest that is coherent with a signal at another measurement location. 
Figure 9 shows the coherence between the two core-exhaust-mounted ITPs for test points 4-7, which correspond to the power settings of $60 \%, 70 \%, 80 \%$, and $90 \%$. Coherence, by definition (and in theory), ranges between zero and unity, where perfect coherence exists at the latter value. Perfect coherence implies a direct linear dependence of one signal on the other. A nonzero coherence value implies the dependence of both signals on a common source in the presence of other unrelated signals at both locations. A zero value implies that the two signals are independent. In practice, where the time series are always finite, a zero coherence value will not be achieved even for perfectly unrelated signals. A statistical estimate is then used to judge if the signals are uncorrelated. This estimate $(95 \%$ confidence level) is shown as the green line in the panels of this figure. Any computed coherence value lower than this limit is not significant and the two signals are considered as fully independent. The broadband coherence displayed between the ITPs for different power settings is above the statistical limit in the region of expected broadband combustor noise, approximately $100-500 \mathrm{~Hz}$, with the upper limit increasing slightly with the power setting. In addition, SPF tones and some harmonics can be identified for the low-pressure and high-pressure spools as well as the fan shaft, with the latter being particularly prominent at higher power settings.

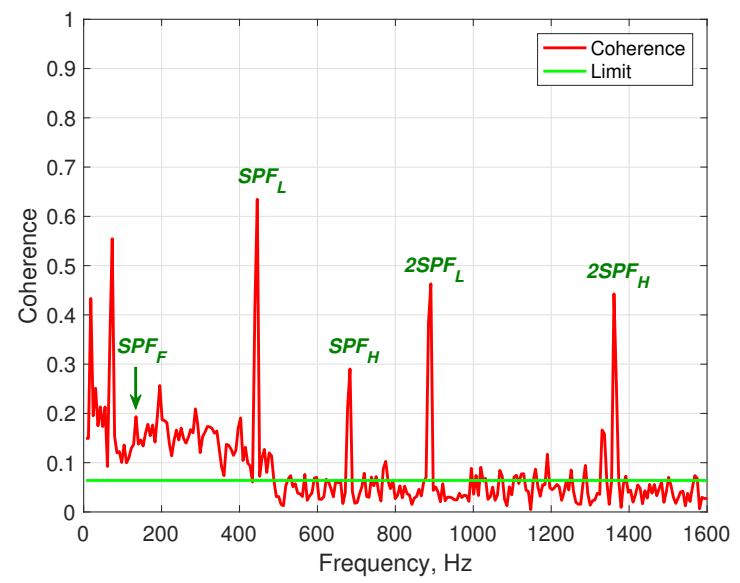

(a)

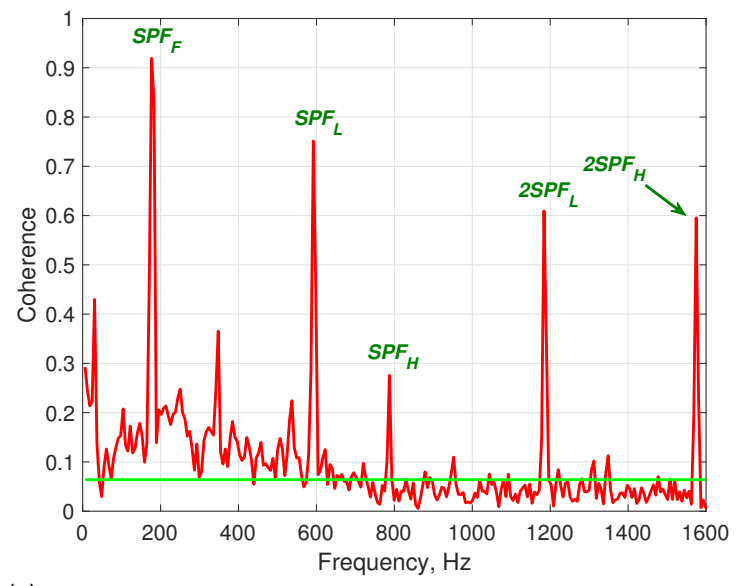

(c)

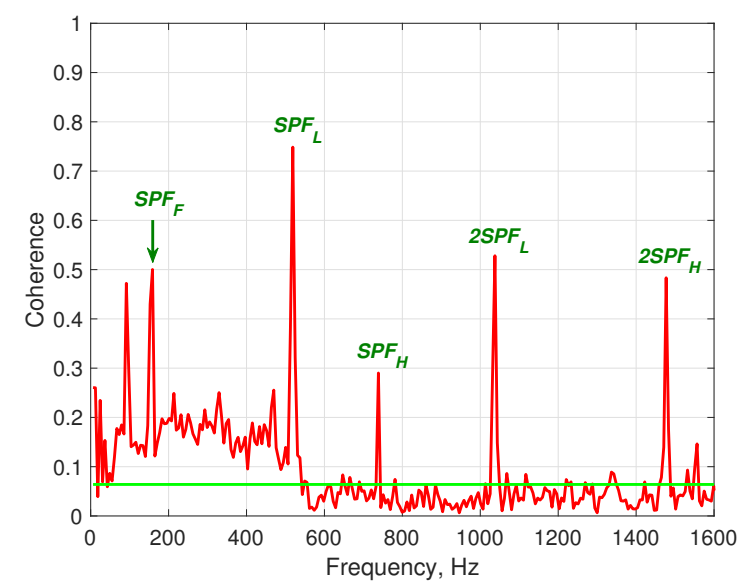

(b)

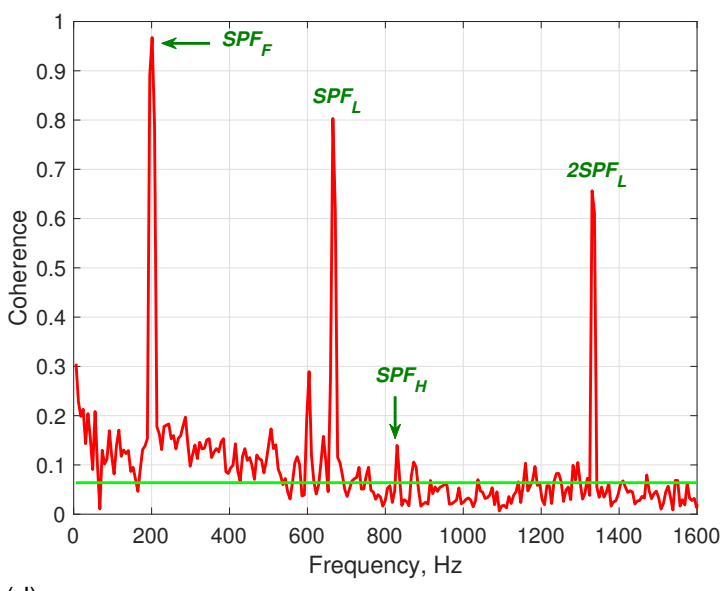

(d)

Figure 9. Coherence between ITPs NE801 (6 o'clock) and NE802 (7 o'clock) signals at a) 60\%, b) 70\%, c) $80 \%$, and d) $90 \%$ power settings

The top panels in Fig. 10 show the total noise signature and the educed combustor-noise component at the midfieldmicrophone location and the $130^{\circ}$ farfield-microphone location for the $60 \%$ power setting. The combustor-noise contribution to the SPL was estimated using the 2-signal coherent output method, Eq. (3), with either the 6 o'clock (red curves) or the 7 o'clock (blue curves) ITP providing the reference signal. The corresponding coherence results are shown in lower panels of this figure. Broadband combustor noise is quite apparent in the expected frequency range of $100-500 \mathrm{~Hz}$ at both the midfield and farfield locations. Additionally, another broadband hump appears in both the midfield and farfield spectra at around $700-1000 \mathrm{~Hz}$ when the 7 o'clock ITP (NE802) serves as a reference. Low- and high-pressure shaft passing frequencies and some harmonics can also be discerned in the coherence at midfield and 
farfield locations.

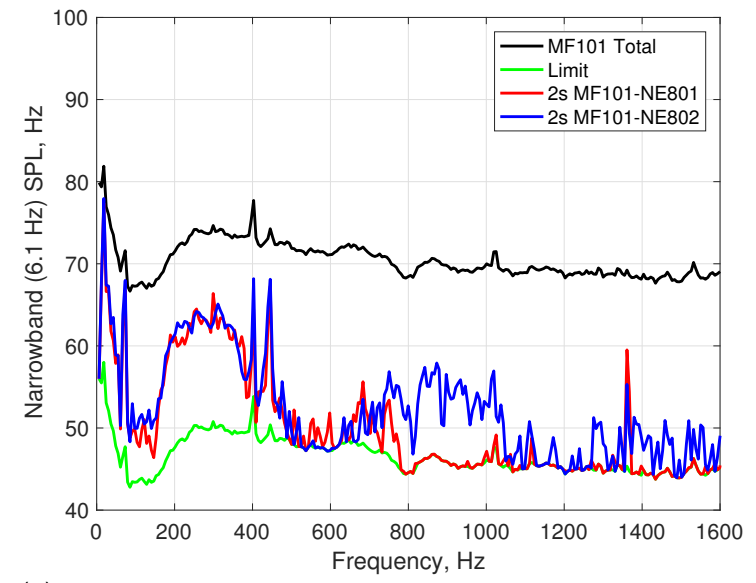

(a)

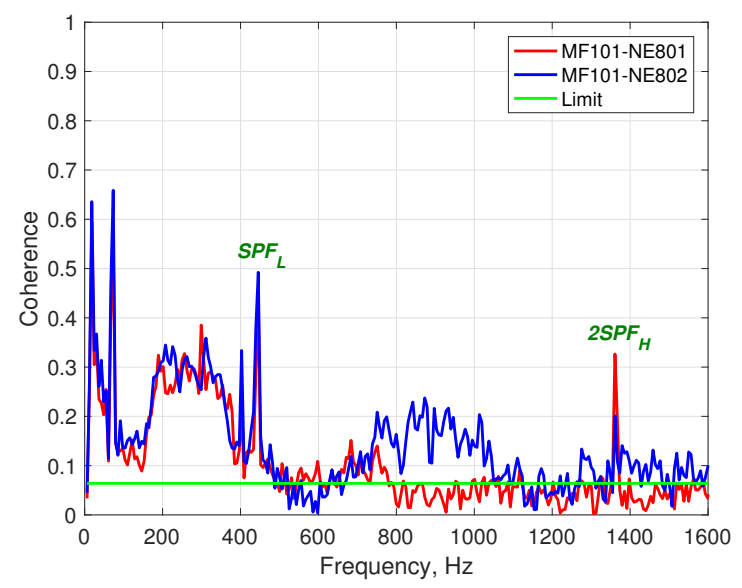

(c)

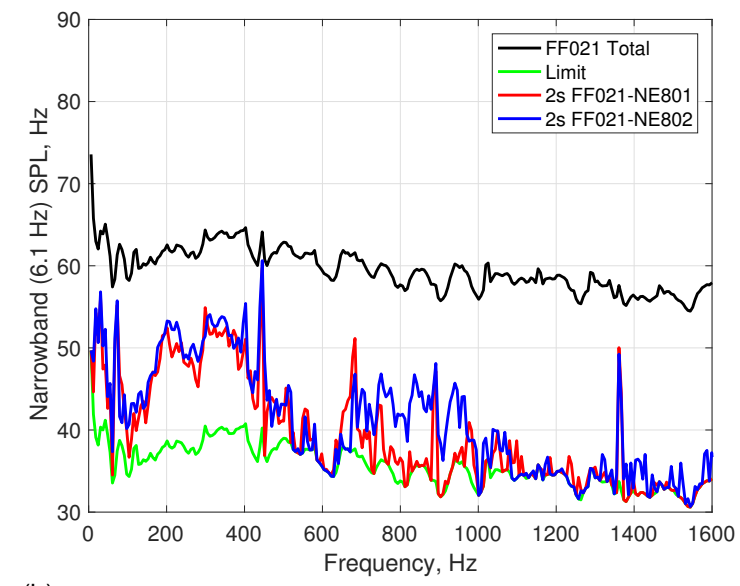

(b)

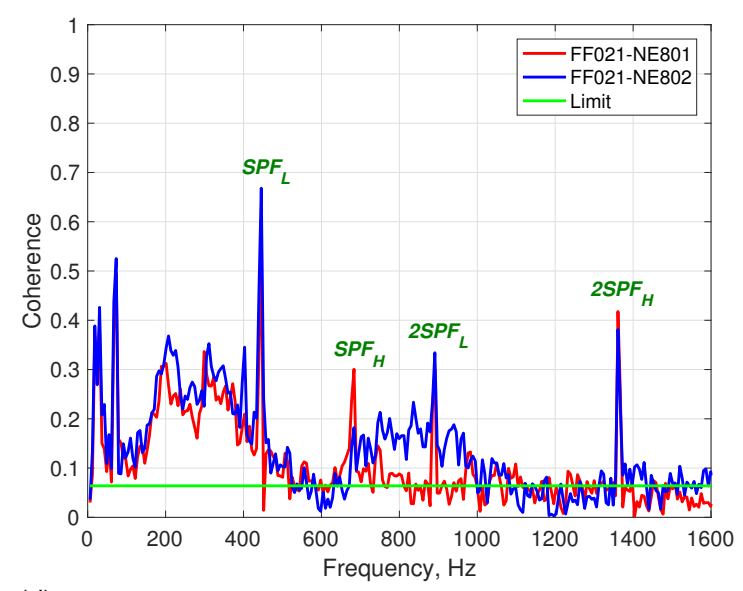

(d)

Figure 10. Midfield (a) and farfield (b) SPL and corresponding coherence (c) and (d) at $60 \%$ power, test point 4 . Educed combustor SPL component and coherence using ITP NE801, 6 o'clock position, (red curves) and ITP NE802, 7 o'clock position, (blue curves)

The estimated duct-mode cut-on/off frequencies at the core-nozzle exit for various power settings are shown in Table A2 based on an engine-deck simulation for the DGEN 380 engine. The frequencies in this table are given to a sufficient number of significant digits so that the trends are clearly displayed. Unfortunately, precise information on how well the simulated conditions describe the actual engine conditions during this test is not available. In addition, the simulation was run for slightly different ambient condition than those of the test. However, an estimate of how representative the simulation is for the actual core-flow conditions can be obtained by comparing the exit-gas temperature provided by the simulation to that reported by the engine control system. This leads to the conclusion that actual and simulated mean-flow data should be within $4 \%$ of each other in the core nozzle.

Based on Eqs. A 1 and A2, it follows that the uncertainty in the predicted duct-mode cut-on/off frequencies is given by

$$
\frac{\left|\Delta f_{c}\right|}{f_{c}} \leqslant \frac{|\Delta c|}{c}+\frac{M^{2}}{\sqrt{1-M^{2}}} \times \frac{|M|}{M} .
$$

Since the core-nozzle flow is hot, the (subsonic) Mach number is going to be rather modest and it can be assumed that the factor multiplying the Mach-number relative error in Eq. (4) is of order unity (or less). Furthermore, the speed of sound to leading order depends on the square root of the static temperature; hence, its relative error should be $2 \%$. Consequently, the Mach-number relative error could be as high as 6\%. This leads to the conclusion that the upper bound on the relative error for the predicted duct-mode cut-on/off frequencies, as they apply to the current test, is $8 \%$.

Using this information in combination with Table A2 shows that the cut-on/off frequency for the $( \pm 1,0)$ duct mode falls somewhere in the range of $730-860 \mathrm{~Hz}$ for the conditions corresponding to Fig. 10 It is therefore con- 
cluded that the second broadband hump in the combustor-noise component is associated with the cut-on of the first azimuthal mode. Why this feature is not visible when the 6 o'clock ITP (NE801) serves as a reference is not clear at present, but this issue will be further explored in a planned upcoming experiment with a more extensive circumferential instrumentation at the core-nozzle exit.

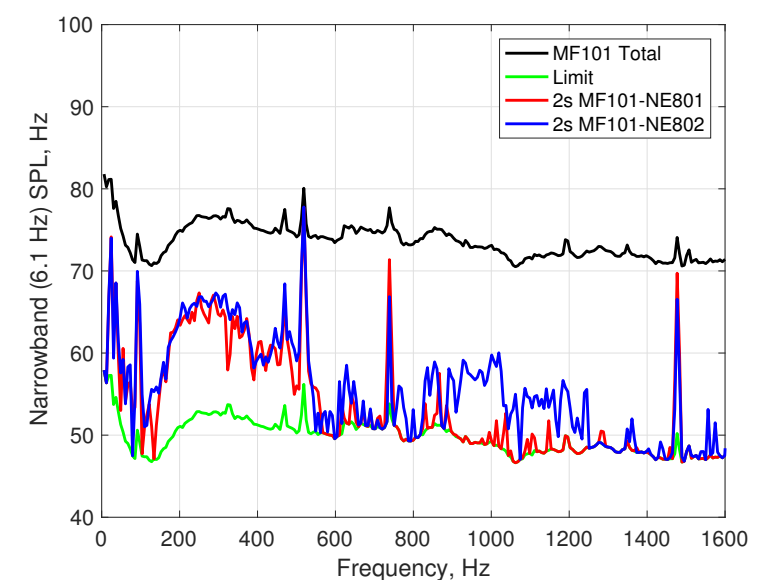

(a)

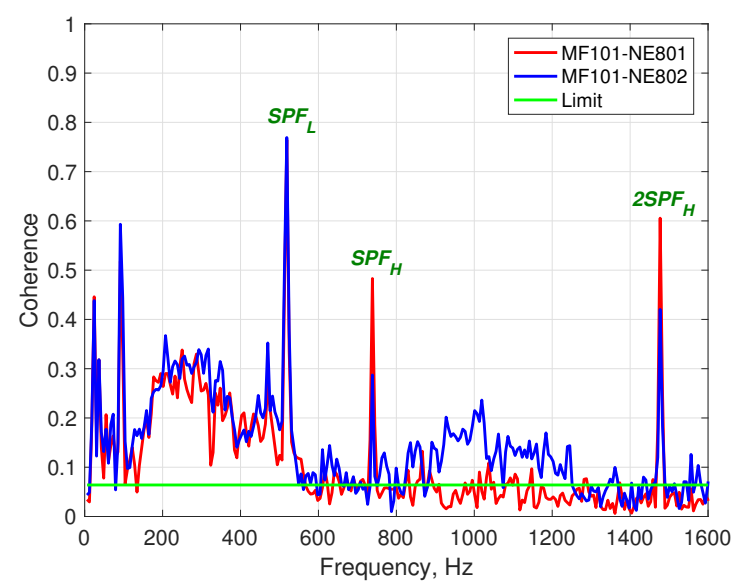

(c)

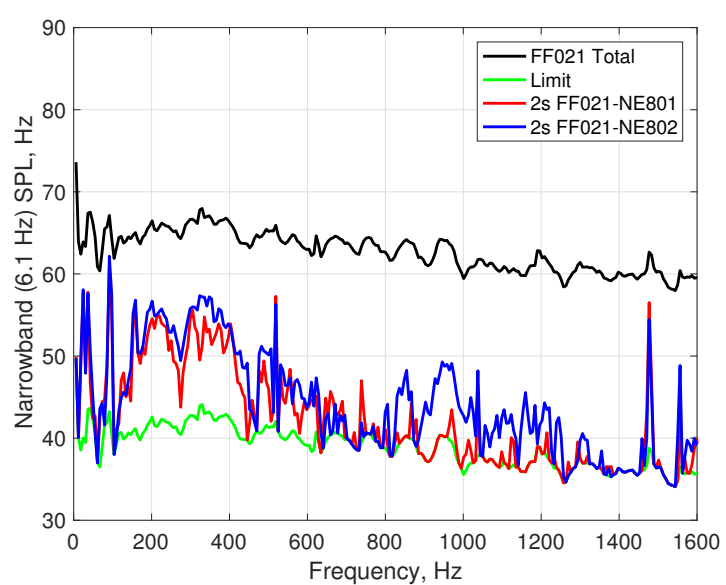

(b)

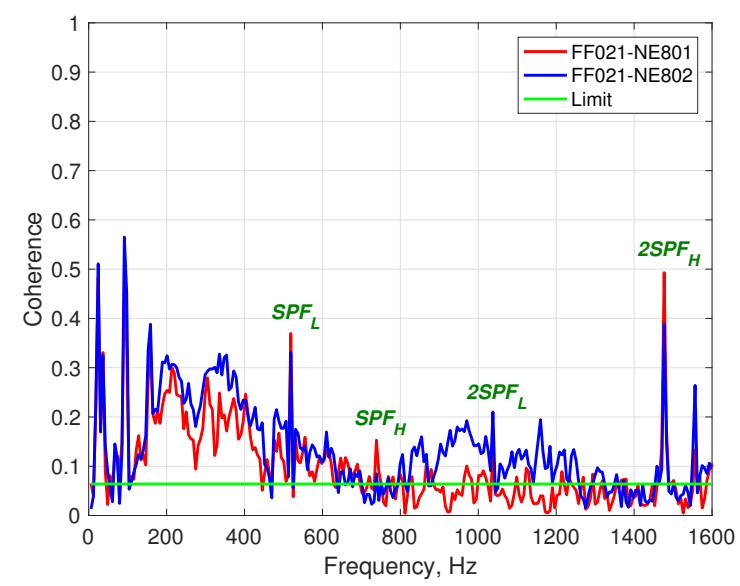

(d)

Figure 11. Midfield (a) and farfield (b) $S P L$ and corresponding coherence (c) and (d) at $70 \%$ power, test point 5 . Educed combustor $S P L$ component and coherence using ITP NE801, 6 o'clock position, (red curves) and ITP NE802, 7 o'clock position, (blue curves)

Figures 11 , 13 show the same information as in Fig. 10 , but for the $70 \%, 80 \%$, and $90 \%$ power settings (test points 5-7), respectively. As can be seen in these figures, the frequency range of combustor-noise component, educed by using either of the two ITPs, increases with the power level. At the 70\% power level, the upper limit is at least $550 \mathrm{~Hz}$. Also, the secondary hump in the two-signal results obtained using the 7 o'clock ITP (NE802) is still clearly identifiable in the spectra. At $80 \%$ and $90 \%$ power, the upper frequency limit of the deduced broadband combustor noise is about $800 \mathrm{~Hz}$ and at least $900 \mathrm{~Hz}$, respectively. It is not clear whether the secondary hump in the combustor-noise spectra, observed at the lower power settings, now is below the levels that can be detected by the present two-signal method or if the two humps have simply merged, i.e. they no longer have a clear demarcation. This latter uncertainty also points to the need for a careful circumferential mapping of the sound field at the core-nozzle exit.

\section{Summary}

An initial analysis of acoustic data acquired during a baseline test using the new DART resource at NASA GRC is presented here. This test is part of an effort to develop a better understanding of the core/combustor-noise source leading to improved mitigation techniques and airport-community-noise prediction methods. The acoustic data are deemed to be of high quality, compares well with results from a quick feasibility test carried out in 2014, and will 


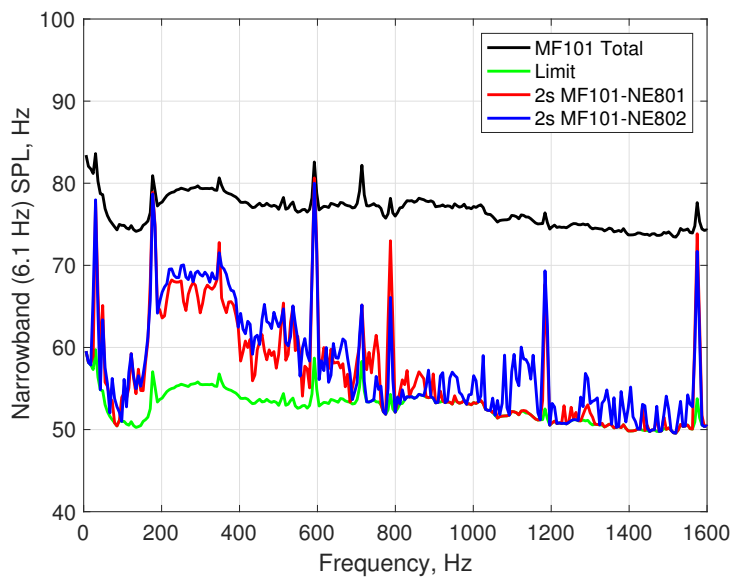

(a)

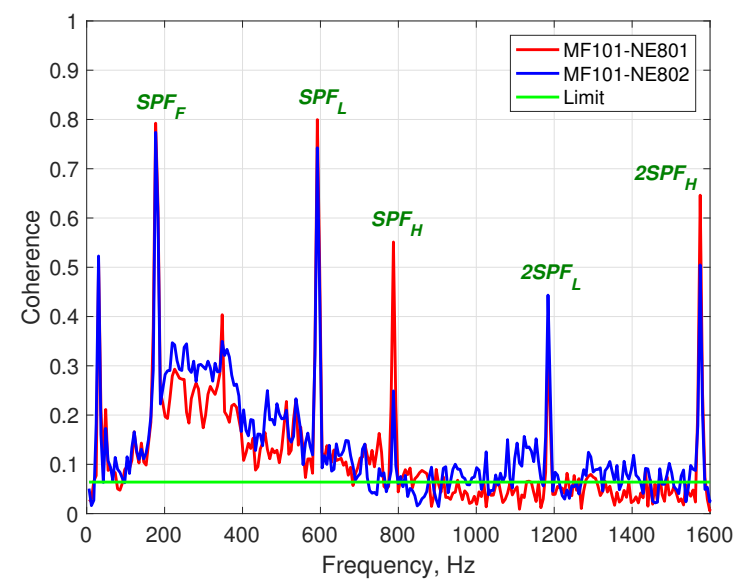

(c)

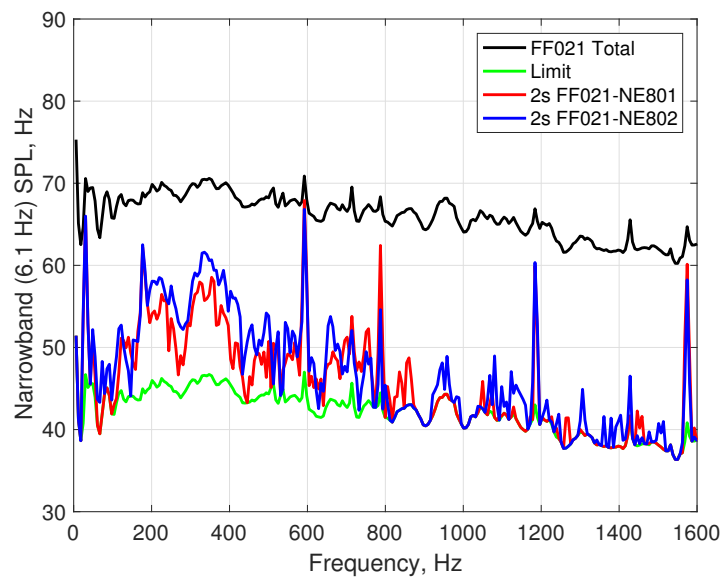

(b)

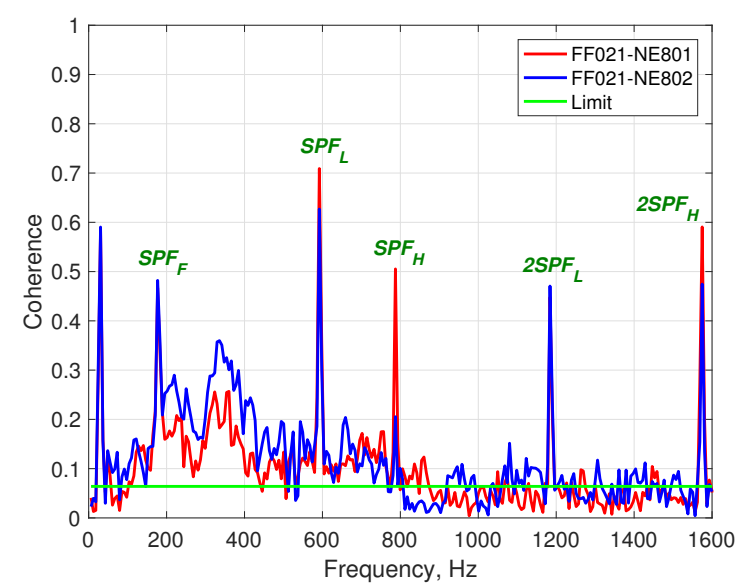

(d)

Figure 12. Midfield (a) and farfield (b) SPL and corresponding coherence (c) and (d) at $80 \%$ power, test point 6 . Educed combustor $S P L$ component and coherence using ITP NE801, 6 o'clock position, (red curves) and ITP NE802, 7 o'clock position, (blue curves)

serve as a solid baseline for future work. Combustor-noise components of total noise signatures are educed using a two-signal source-separation method and are found to occur in the expected frequency range. The results also suggest that both the plane-wave mode and the first azimuthal mode, are present at the core-nozzle exit for this turbofan engine- which will be further investigated in the near future.

\section{APPENDIX}

\section{A. Cut-On/Off Helmholtz Number}

The confined geometry leads to the existence of a multitude of acoustic modes, $(m, n)$, where $m$ and $n$ denote the azimuthal and radial mode numbers, respectively in the engine-internal passageways of turbofans. The plane wave mode $(0,0)$ can always propagate, but the other modes can only propagate if the frequency is higher than a mode-dependent cut-on/off value. If the frequency is less than this value, the mode is evanescent.

In the absence of any significant swirl, which is generally the situation in inter-turbine ducts and nozzles, a common leading-order approximation is to assume the mean flow as locally uniform with constant properties. See Eversman ${ }^{6}$ for a discussion of duct acoustics and a comprehensive list of references. If the frequency of the acoustic mode is expressed in terms of the nondimensional Helmholtz number, i.e.

$$
\omega=2 \pi f_{*} b_{*} / c_{*},
$$

where $f_{*}, b_{*}$, and $c_{*}$ are the dimensional frequency, outer duct radius, and local speed of sound, respectively, it turns 


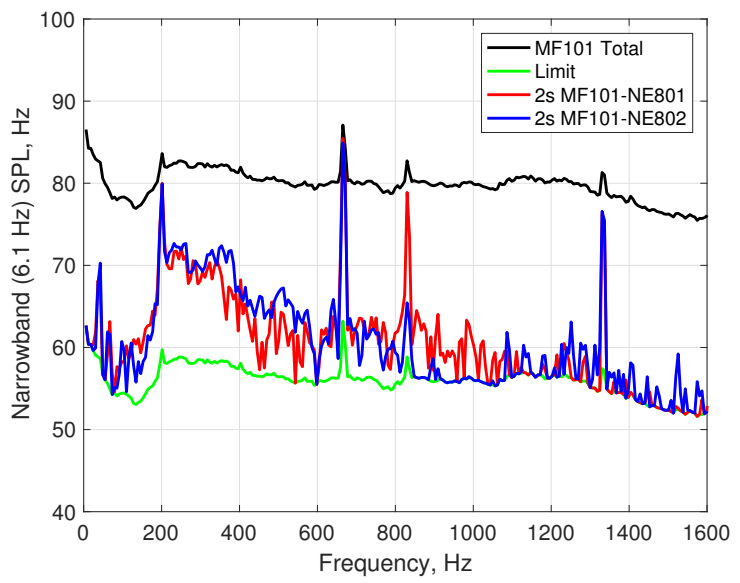

(a)

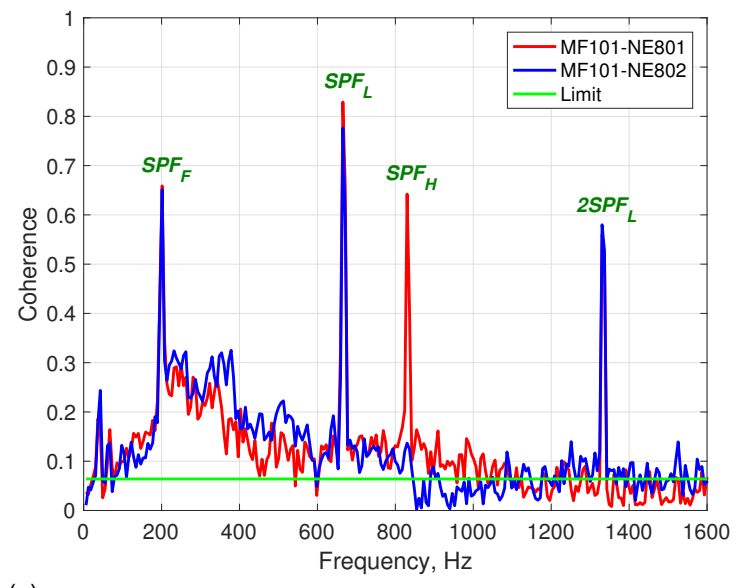

(c)

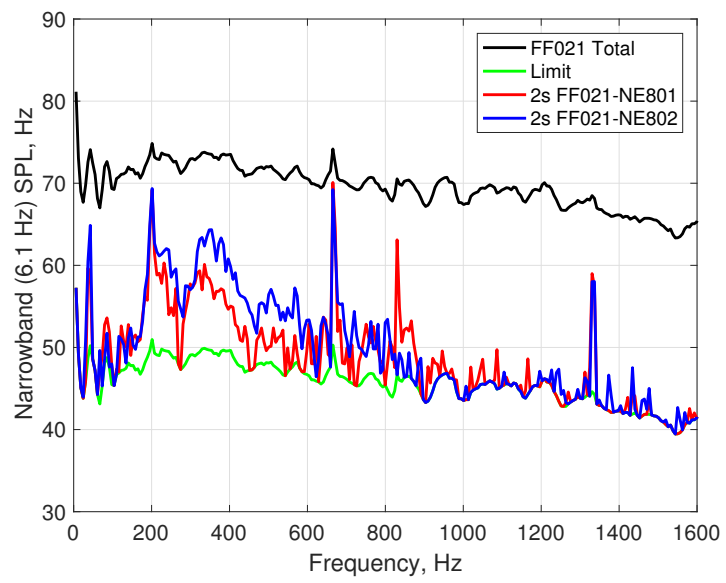

(b)

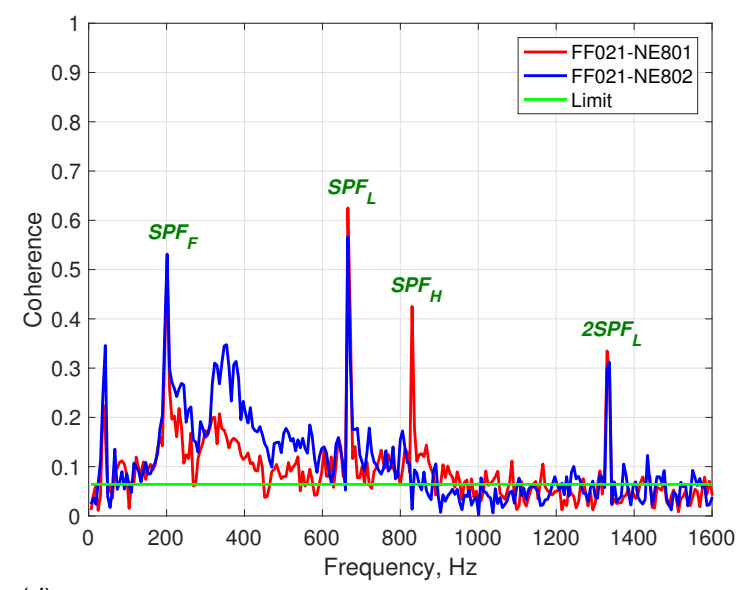

(d)

Figure 13. Midfield (a) and farfield (b) SPL and corresponding coherence (c) and (d) at $80 \%$ power, test point 6 . Educed combustor $S P L$ component and coherence using ITP NE801, 6 o'clock position, (red curves) and ITP NE802, 7 o'clock position, (blue curves)

out that the cut-on/off value is given by

$$
\omega_{m n_{c}}=\sqrt{1-M^{2}} \lambda_{m n},
$$

where $0 \leqslant M<1$ is the local Mach number. The $\lambda_{n m}$ are the roots of

$$
Y_{m}^{\prime}\left(\lambda_{m n} a\right) J_{m}^{\prime}\left(\lambda_{m n}\right)-J_{m}^{\prime}\left(\lambda_{m n} a\right) Y_{m}^{\prime}\left(\lambda_{m n} r\right)=0, \quad n=0,1, \ldots,
$$

where $J_{m}$ and $Y_{m}$ are the Bessel functions of the first and second kind of order $\mathrm{m}$, the prime indicates derivative with respect to the argument, and $a$ is the nondimensional inner radius of the duct. The eigenvalue index $\mathrm{n}$ is referred to as the radial mode order and indicates the number of pressure nodes (zeroes) in the radial profile. Note that the eigenvalues $\lambda_{m n}$ for hard-wall ducts are real and form an infinite set. Moreover, $\lambda_{m n}$ only depends on the nondimensional inner radius, $a$, i.e. the duct geometry, and hence can be interpreted as the no-flow cut-on/off Helmholtz number, $\omega_{m n_{c}}^{(0)}=\lambda_{m n}$.

Table A 1 lists a sample of the eigenvalues $\lambda_{m n}$, i.e. the roots of Eq. (A3), to four decimal places for a $=0.805$, which corresponds to the geometry at the core-nozzle exit. The plane-wave (or bulk) modes $(0,0)$ are always cut on. Note that as the Helmholtz number is increased from zero, the $(\mathrm{m}, 0)$ modes, with $\pm m=1-14$ are successively cut on before the first radial mode $(0,1)$ is cut on. It turns out that the cut-on/off Helmholtz numbers for radial modes $(n \neq 0)$ increase with decreasing duct height. This is the reason why so many azimuthal modes are sequentially cut on before the first radial mode can propagate in this case. The cut-on/off Helmholtz number for any subsonic Mach number can now be calculated using Table A 1 and Eq. A2. 
Table A 1. No-flow cut-on/off Helmholtz Numbers, $\lambda_{m n}$, for an annular duct with $a=0.805$

\begin{tabular}{|c|c|c|c|c|c|}
\hline & $\mathrm{n}=0$ & $\mathrm{n}=1$ & $\mathrm{n}=2$ & $\mathrm{n}=3$ & $\mathrm{n}=4$ \\
\hline $\mathrm{m}=0$ & 0 & 16.1394 & 32.2359 & 48.3418 & 64.4502 \\
$\mathrm{~m}=1$ & 1.1102 & 16.1783 & 32.2552 & 48.3547 & 64.4598 \\
$\mathrm{~m}=2$ & 2.2200 & 16.2944 & 32.3131 & 48.3933 & 64.4887 \\
$\mathrm{~m}=3$ & 3.3295 & 16.4863 & 32.4094 & 48.4575 & 64.5369 \\
$\mathrm{~m}=4$ & 4.4382 & 16.7514 & 32.5437 & 48.5472 & 64.6043 \\
$\mathrm{~m}=5$ & 5.5459 & 17.0864 & 32.7156 & 48.6624 & 64.6908 \\
$\mathrm{~m}=6$ & 6.6524 & 17.4877 & 32.9245 & 48.8028 & 64.7964 \\
$\mathrm{~m}=7$ & 7.7575 & 17.9509 & 33.1697 & 48.9683 & 64.9210 \\
$\mathrm{~m}=8$ & 8.8609 & 18.4718 & 33.4505 & 49.1585 & 65.0645 \\
$\mathrm{~m}=9$ & 9.9624 & 19.0459 & 33.7659 & 49.3732 & 65.2268 \\
$\mathrm{~m}=10$ & 11.0618 & 19.6689 & 34.1152 & 49.6121 & 65.4076 \\
$\mathrm{~m}=11$ & 12.1588 & 20.3366 & 34.4971 & 49.8748 & 65.6069 \\
$\mathrm{~m}=12$ & 13.2534 & 21.0452 & 34.9108 & 50.1610 & 65.8246 \\
$\mathrm{~m}=13$ & 14.3452 & 21.7910 & 35.3552 & 50.4703 & 66.0603 \\
$\mathrm{~m}=14$ & 15.4342 & 22.5707 & 35.8291 & 50.8022 & 66.3140 \\
$\mathrm{~m}=15$ & 16.5202 & 23.3814 & 36.3314 & 51.1564 & 66.5855 \\
$\mathrm{~m}=16$ & 17.6031 & 24.2201 & 36.8610 & 51.5324 & 66.8744 \\
\hline
\end{tabular}

Mean-line data needed to convert the no-flow cut-on/off Helmholtz numbers to dimensional frequencies at flow conditions, using Eqs. (A1) and (A2), were obtained using an engine-deck simulation for the DGEN 380 turbofan. Table A2 shows the resulting estimated cut-on/off frequencies for select duct modes at the core-nozzle exit at the $60 \%$, $70 \%, 80 \%$, and $90 \%$ power settings. As can be seen in this table, the radial $(n \neq 0)$ duct-mode frequencies are well outside of the range of interest for combustor noise.

Table A 2. Select estimated cut-on/off duct-mode frequencies $(\mathrm{Hz})$ at the core-nozzle exit at $60 \%, 70 \%, 80 \%$ and $90 \%$ power

\begin{tabular}{|c|c|c|c|c|c|}
\hline Power & & $\mathrm{n}=0$ & $\mathrm{n}=1$ & $\mathrm{n}=2$ & $\mathrm{n}=3$ \\
\hline $60 \%$ & $\mathrm{~m}=0$ & 0 & 11,532 & 23,033 & 34,541 \\
& $\mathrm{~m}=1$ & 793 & 11,559 & 23,047 & 34,550 \\
& $\mathrm{~m}=2$ & 1,586 & 11,642 & 23,088 & 34,577 \\
& $\mathrm{~m}=3$ & 2,378 & 11,779 & 23,157 & 34,623 \\
\hline $70 \%$ & $\mathrm{~m}=0$ & 0 & 11,491 & 22,951 & 34,417 \\
& $\mathrm{~m}=1$ & 790 & 11,518 & 22,964 & 34,426 \\
& $\mathrm{~m}=2$ & 1,580 & 11,601 & 23,005 & 34,454 \\
& $\mathrm{~m}=3$ & 2,370 & 11,738 & 23,074 & 34,500 \\
\hline $80 \%$ & $\mathrm{~m}=0$ & 0 & 11,465 & 22,900 & 34,341 \\
& $\mathrm{~m}=1$ & 789 & 11,493 & 22,913 & 34,350 \\
& $\mathrm{~m}=2$ & 1,577 & 11,575 & 22,954 & 34,377 \\
& $\mathrm{~m}=3$ & 2,365 & 11,711 & 23,023 & 34,423 \\
\hline $90 \%$ & $\mathrm{~m}=0$ & 0 & 11,414 & 22,797 & 34,187 \\
& $\mathrm{~m}=1$ & 785 & 11,441 & 22,810 & 34,196 \\
& $\mathrm{~m}=2$ & 1,570 & 11,523 & 22,851 & 34,223 \\
& $\mathrm{~m}=3$ & 2,355 & 11,659 & 22,919 & 34,268 \\
\hline
\end{tabular}




\section{References}

${ }^{1}$ Berton, J. B., Envia, E., and Burley, C. L., "An Analytical Assessment of NASA's N+1 Subsonic Fixed Wing Project Noise Goal," AIAA Paper 2009-3144, 16th AIAA/CEAS Aerocoustics Conference, Miami, Florida, 2009.

${ }^{2}$ Hultgren, L. S., Miles, J. H., and Jorgenson, P. C. E., "Engine System and Core Noise," Assessment of NASA's Aircraft Noise Prediction Capability, edited by M. D. Dahl, chap. 3, NASA/TP-2012-215653, 2012, pp. 35-62.

${ }^{3}$ Hultgren, L. S., "A First Look at the DGEN380 Engine Acoustic Data From a Core-Noise Perspective," Tech. Rep. NASA/TM-2015-218924, NASA, 2015.

${ }^{4}$ Bendat, J. S. and Piersol, A. G., Engineering Applications of Correlation and Spectral Analysis, Wiley-Interscience, 1980.

${ }^{5}$ Ahuja, K. K., "Designing Clean Jet-Noise Facilities and Making Accurate Jet-Noise Measurements," International J. Aeroacoustics, Vol. 2 , No. 3\&4, 2003, pp. 371-412.

${ }^{6}$ Eversman, W., "Theoretical Models for Duct Acoustic Propagation and Radiation," Aeroacoustics of Flight Vehicles: Theory and Practice, edited by H. H. Hubbard, Vol. 2, chap. 13, NASA Reference Publication 1258, WRDC Technical Report 90-3052, 1991, pp. 101-163.

\section{Acknowledgments}

This work is supported by the NASA Advanced Air Vehicles Program, Advanced Air Transport Technology Project, under the Aircraft Noise Reduction Subproject. The AAPL staff are thanked for their expertise and dedication in preparing and executing the 2017 test campaign. Joseph W. Connolly of the NASA GRC Intelligent Control and Autonomy Branch is thanked for previously supplying relevant engine operational parameters obtained from the DGEN SIMMOT simulation system.

Trade names and trademarks are used in this report for identification only. Their usage does not constitute an official endorsement, either expressed or implied, by the National Aeronautics and Space Administration. 